\title{
Spontaneous rupture of an unscarred uterus during pregnancy: an interesting case report
}

\section{Durga K.*}

Department of Obstetrics and Gynecology, Sri Lakshmi Narayana Institute of Medical Sciences, Bharath University, Osudu, Puducherry, India

Received: 28 August 2017

Accepted: 25 September 2017

\section{*Correspondence:}

Dr. Durga K.,

E-mail: drdurgakrish@gmail.com

Copyright: (c) the author(s), publisher and licensee Medip Academy. This is an open-access article distributed under the terms of the Creative Commons Attribution Non-Commercial License, which permits unrestricted non-commercial use, distribution, and reproduction in any medium, provided the original work is properly cited.

\begin{abstract}
Uterine rupture in pregnancy is very rare and potentially catastrophic for both mother and foetus. The most common cause of uterine rupture is giving away of previous caesarean uterine scar. Spontaneous rupture of an unscarred uterus during pregnancy is a rare occurrence. We hereby present a rare case of a spontaneous complete uterine rupture in a non-labouring unscarred uterus of a 33-year-old nulliparous woman at 35 weeks of gestation. She presented with lower abdomen pain and decreased foetal movements at Institute of Obstetrics and Gynaecology, Chennai. Even before getting into labour, patient suddenly collapsed, and emergency laparotomy was proceeded in view of suspicious concealed abruption. There was frank hemoperitoneum along with a dead baby in the abdominal cavity. There was rupture of uterine fundus extending from one cornual end to the other and closure of uterine rent proceeded. Spontaneous rupture of uterus occurs when there is an upper segment uterine scar. She had a past history of eventful uterine curettage which was the risk factor for uterine rupture.
\end{abstract}

Keywords: Pregnancy, Spontaneous uterine rupture, Unscarred uterus, Uterine curettage

\section{INTRODUCTION}

Rupture of the pregnant uterus is an obstetric and surgical emergency that can lead to maternal and foetal death. Previous uterine surgery is the most common risk factor. Rupture of the unscarred uterus is rare, but appears to account for an increasing proportion of all uterine ruptures. ${ }^{1}$ Overall incidence of rupture of uterus during pregnancy is 1 in 1,536 pregnancies $(0.07 \%))^{2}$ The maternal and foetal prognosis are bad especially when the rupture occurs in an unscarred uterus. The normal, unscarred uterus is least susceptible to rupture, the rate being 1 in 8,434 pregnancies $(0.012 \%){ }^{2}$ The incidence is significantly higher in developing countries than developed countries, possibly related to higher parity, longer labors, and a higher frequency of contracted pelvis in these areas, as well as a frequent lack of access to emergency obstetrical services. ${ }^{3,4}$

Congenital uterine anomalies, multiparity, previous uterine myomectomy, the number and type of previous caesarean deliveries, foetal macrosomia, labor induction, uterine instrumentation, and uterine trauma all increase the risk of uterine rupture, whereas previous successful vaginal delivery and a prolonged interpregnancy interval after a previous caesarean delivery may confer relative protection.

We hereby report a case of spontaneous uterine rupture at 35 weeks and 1 day of gestation in a non-labouring patient who has never had a previous uterine surgery, but who had an uterine curettage for abortion. 


\section{CASE REPORT}

A woman, 33 years of age, gravida 2 abortion 1, was admitted at Institute of Obstetrics and Gynaecology, Chennai on $27^{\text {th }}$ November 2011 at 4.00 am at 35 weeks and 1 day of gestation with complaints of lower abdomen pain and decreased fetal movements past three hours. Her last menstrual period was on $24^{\text {th }}$ March 2011. Her first obstetric event was a missed abortion at 45 days amenorrhea for which dilatation and curettage was done at a local village 3 year back. She had a history of oneyear amenorrhea. She underwent treatment for the same at a renowned private hospital in Chennai where hysteroscopy and subsequent infertility treatment with ovulation induction drugs was done. This second pregnancy was booked at the same hospital where serial ultrasound scans were done in the $1^{\text {st }}, 2^{\text {nd }}$ and $3^{\text {rd }}$ trimester which showed a fetus at 35 weeks of gestation in cephalic presentation with placenta attached to the posterior and right lateral wall of uterus and adequate amniotic fluid. No history of insertion of contraceptive devices after her abortion. She was not a known case of pre-eclampsia, hypertension, diabetes, heart disease, epilepsy, tuberculosis or bronchial asthma. There was no significant family history.

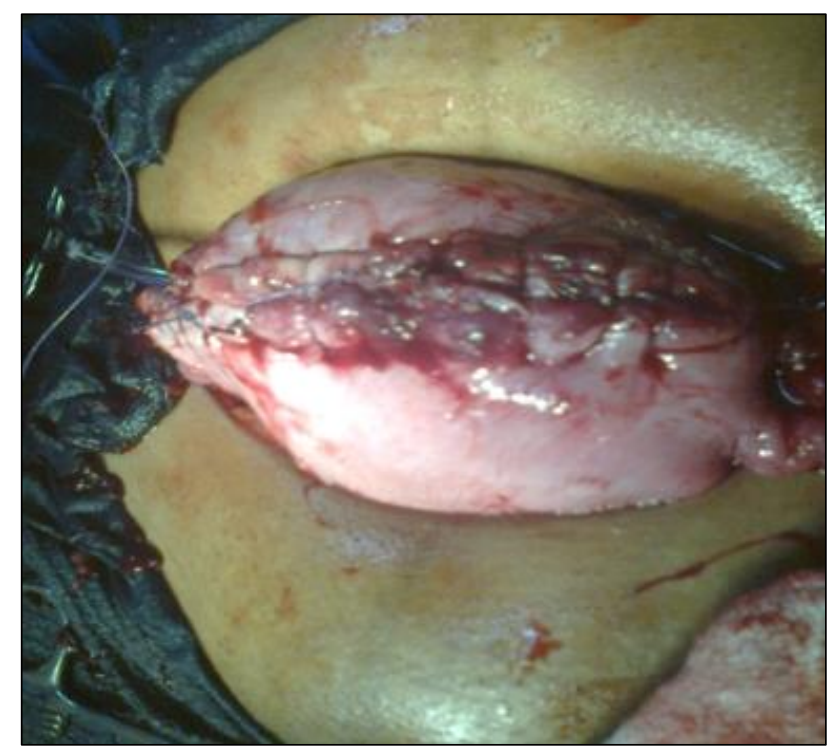

Figure 1: Fundal rupture of uterus, rent closed.

On admission she was comfortable, not anemic, her vitals were stable, and she was not in labor. On clinical examination the uterus corresponded to 34 weeks of gestation, relaxed, not acting, not tense, not tender, fetal head was unengaged, $4 / 5^{\text {th }}$ palpable per abdomen and the heart rate was good. Per vaginum examination revealed a soft, uneffaced cervix of $3 \mathrm{~cm}$ in length, os admitting 1 finger with head at brim. The admission non-stress test was found to be reactive. She was able to feel good fetal movements within half an hour of admission. Her blood group was B Rhesus positive. Her complete blood count was found to be within normal limits. Haemoglobin: 12 gm \%, Packed cell volume: $32 \%$, platelets: normal, blood sugar: $104 \mathrm{mg} \%$. Urine examination for albumin/sugar was nil.

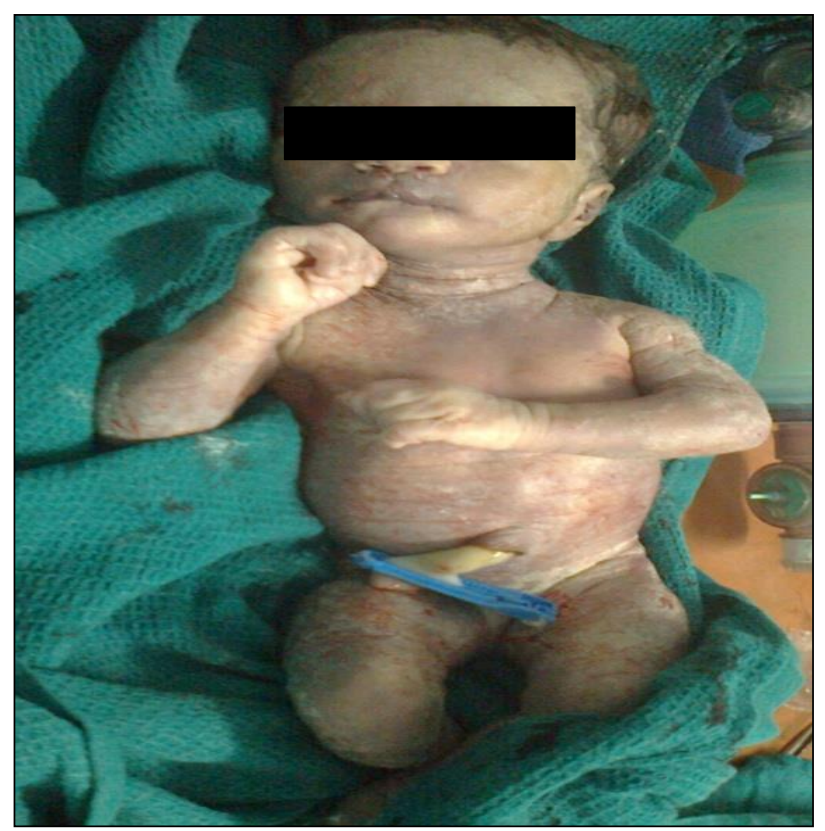

Figure 2: Term intrauterine death.

After 12 hours of admission she complained of acute epigastric pain associated with giddiness. Within few seconds she collapsed. She became extremely pale with tachypnea, tachycardia and low volume pulse. Her blood pressure dropped to $90 / 60 \mathrm{~mm}$ of $\mathrm{Hg}$ and $\mathrm{SPO}_{2}$ was $98 \%$. Abdomen examination revealed tense and tender uterus of 34 weeks of gestation with no detectable uterine activity. There was also abdomen distension and the fetal heart sound was not detectable. Her vaginal examination revealed the same findings as on admission. A clinical diagnosis of concealed abruption was made. Her coagulation profile was normal. With ongoing resuscitative measures $(100 \% 02$ by face mask crystalloids, colloids) patient was prepared for emergency laparotomy. Under general anesthesia, abdomen was opened by suprapubic transverse incision. Frank hemoperitoneum of approximately $1000 \mathrm{ml}$ of fresh blood was drained. Baby was found lying within the peritoneal cavity and was immediately delivered within 20 minutes of diagnosis. It was a fresh, dead born, preterm girl baby weighing $2.2 \mathrm{~kg}$. The gravid uterus was given away along its entire length at the fundal region extending from one cornual end to the other. The placenta was within the uterine cavity and was removed in toto. There was no extension of the tear. Broad ligaments were found to be intact on either side. There was no undue bleeding intraoperatively. The uterine rent was sutured in two layers with 1-0 vicryl and since the cornual end was also involved, the same could not be spared. There is doubt of future fertility because of the involvement of cornual end. Per operatively 3 units of blood was transfused. 
The diagnosis of rupture uterus was made intraoperatively. Abdomen closed after securing perfect hemostasis. Post operatively 2 units of packed cells and 4 units of FFP transfused for an estimated blood loss of about $1000 \mathrm{ml}$. She was put on higher antibiotics (Inj. Cefotaxim $1 \mathrm{gm}$ iv bd, inj. Gentamycin $80 \mathrm{mg}$ iv bd, inj. Metronidazole $400 \mathrm{mg}$ iv bd for 5 days). The postoperative period was uneventful. Suture removal was done on the $8^{\text {th }}$ post-operative day and the patient was discharged on the $10^{\text {th }}$ post-operative day with the advice of contraception for two years and she was explained about the chances of future pregnancy. Her discharge hemoglobin was $9.5 \mathrm{gm} \%$. In view of the risk of early rupture of uterus in future pregnancy, she was advised early hospitalization at 28 weeks of gestation.

\section{DISCUSSION}

Uterine rupture during pregnancy is a rare occurrence that frequently results in life-threatening maternal and fetal compromise, whereas uterine scar dehiscence is a more common event that seldom results in major maternal or fetal complications. By definition, uterine scar dehiscence constitutes separation of a preexisting scar that does not disrupt the overlying visceral peritoneum (uterine serosa) and that does not significantly bleed from its edges. In addition, the fetus, placenta, and umbilical cord must be contained within the uterine cavity, without a need for cesarean delivery due to fetal distress. By contrast, uterine rupture is defined as a full-thickness separation of the uterine wall and the overlying serosa.

Uterine rupture is associated with (i) clinically significant uterine bleeding (ii) fetal distress (iii) expulsion or protrusion of the fetus, placenta, or both into the abdominal cavity and (iv) the need for prompt cesarean delivery and uterine repair or hysterectomy.

Spontaneous ruptures are usually intrapartum and associated with risk factors such as uterine abnormalities, grandmultiparity, macrosomic fetus, cephalopelvic disproportion and uterine trauma from prior instrumentation from abortion, version and oxytocin stimulation. ${ }^{5}$ Risk factors associated with early uterine rupture in pregnancy include previous salpingectomy and cornual resection following ectopic pregnancy, trauma, myomectomy, congenital abnormalities and sacculation of the entrapped retroverted uterus. ${ }^{6}$

Maternal mortality from uterine rupture is rare in developed countries unlike in developing countries where it ranges from $5 \%$ to $15 \%$ and fetal loss can exceed $80 \%$. $^{3}$ The initial signs and symptoms of uterine rupture are typically nonspecific, which makes diagnosis difficult and sometimes delays definitive therapy. The signs and symptoms of uterine rupture largely depend on the timing, site, and extent of the uterine defect. Uterine rupture at the site of a previous uterine scar is typically less violent and less dramatic than a spontaneous or traumatic rupture because of their relatively reduced vascularity.

The classic signs and symptoms of uterine rupture are

- Fetal distress (Prolonged, late, or recurrent variable decelerations or fetal bradycardia are often the first and only signs of uterine rupture)

- Loss of uterine contractility

- Abdominal pain

- Recession of the presenting fetal part

- Diminished baseline uterine pressure

- Hemorrhage

- Shock.

From the time of diagnosis to delivery, only 10-37 minutes are available before clinically significant fetal morbidity becomes inevitable. Fetal morbidity occurs as a result of catastrophic haemorrhage, fetal anoxia, or both.

In this case the probable cause could be an uterine scar due to an unrecognized incomplete or complete perforation during uterine curettage. The perforation may have been situated at the uterine fundus and subsequently the products of conception of the current pregnancy may have embedded itself in that region, so that when there was a continuous distension of uterus with the evolving pregnancy, there was a stretch of the weakened area finally leading to rupture and expulsion of fetus into the peritoneal cavity. This hypothesis has already been made by Beven et al. ${ }^{7}$

Our first clinical diagnosis was concealed abruption because of the sudden collapse of the non-laboring patient who was not known to have had an uterine scar. The diagnosis of uterine rupture was made intraoperatively only after visualizing the hemoperitoneum. With such a catastrophic fundal rupture our intention was to save the mother. Since there was no active bleeding from the ruptured site and the patient was a nullipara we opted for rent closure so as to preserve the uterus. The good recovery of the patient in the postoperative period was due to the prompt surgical intervention, the retraction phenomenon of the uterus, antibiotic coverage and adequate blood replacement.

The patient was explained about the chances of future pregnancies. In view of high risk of subsequent uterine rupture in future pregnancy, she was advised contraception for two years so that a healthy scar would be formed and about early hospitalization at 28 weeks of gestation.

\section{CONCLUSION}

Uterine rupture occurring on an unknown scarred uterus is sometimes an unpredictable event. It is associated with very poor maternal and fetal prognosis. Usually it occurs during labour, but sometimes as in our case it may occur 
even during pregnancy. This case report showed that previous uterine curettage is a risk factor for uterine rupture due to unnoticed uterine perforation.

The most consistent early indicator of uterine rupture is the onset of a prolonged, persistent, and profound fetal bradycardia. Ultrasound and external electronic fetal heart monitoring are essential to diagnose rupture uterus earlier. Although it has been recommended that hysterectomy has to be carried out in fundal rupture of gravid uterus to save the mother, we feel that management should be tailored to the individual patient, as in this case, on the basis of factors such as parity, extent of the defect and magnitude of bleeding.

Funding: No funding sources Conflict of interest: None declared

Ethical approval: Not required

\section{REFERENCES}

1. Porreco RP, Clark SL, Belfort MA. The changing spectrum of uterine rupture. Am J Obstet Gynecol. 2009;200:269.e1.

2. Gurudut KS, Gouda HS, Aramani SC, Patil RH. Spontaneous rupture of unscarred gravid uterus. J Forensic Sci. 2011;56:S263-5.
3. Hofmeyr GJ, Say L, Gülmezoglu AM. WHO systematic review of maternal mortality and morbidity: the prevalence of uterine rupture. BJOG 2005;112:1221-8.

4. Ekpo EE. Uterine rupture as seen in the University of Calabar Teaching Hospital, Nigeria: a five-year review. J Obstet Gynaecol. 2000;20:154.

5. Sweeten KM, Graves WK, Athanassiou A. Spontaneous rupture of the unscarred uterus. Am J Obstet Gynecol. 1995;172:1851-6.

6. Arbab F, Boulieu D, Bied V, Payan F, Lornage J, Guerin JF. Uterine rupture in first or second trimester of pregnancy after in-vitro fertilization and embryo transfer. Hum Reprod. 1996;11:1120-2.

7. Bevan JR, Marley NJE, Ozumba EN. Uterine rupture, placenta percreta and curettage in early pregnancy, case report. $\mathrm{Br} \mathrm{J}$ Obstet Gynaecol. 1985;92(6):642-5

Cite this article as: Durga K. Spontaneous rupture of an unscarred uterus during pregnancy: an interesting case report. Int J Reprod Contracept Obstet Gynecol 2017;6:5642-5. 